\title{
Designing Urban Experience for Beijing in the Context of Smart City
}

\author{
Zhiyong Fu \\ Department of Information Art and Design, Tsinghua University, \\ 100084 Beijing, China \\ fuzhiyong@tsinghua.edu.cn
}

\begin{abstract}
This paper will explore the urban experience and design opportunities in the context of smart city. Shaping the ecological, balanced and sustainable way of urban lifestyle is becoming new challenge to designer in China. In related research, the development of smart cities and design urban experience will be explored from the integrated perspectives of theories and methodologies. We regard the city as the social network, living community and connected organism by the support of new information and communication technology. Research will focus on understanding the urban interaction pattern between citizen, media and city based on activity theory. The results of this research will help to transform the smart city design from technology driven to people driven; provide new models and case studies for developing the smart service system and shaping new urban experience in Beijing.
\end{abstract}

Keywords: Urban experience, Activity theory, Interaction Design, Service design, Smart city.

\section{Introduction}

In this paper, the methods of designing urban experience will be explored from the theoretical and practical levels. Urban experience can be achieved through urban activities and social network; it is dynamic personal reflection of urban lifestyle, and changed with the time lapse and context transformation.

Designing urban experience usually focuses on exploring physical city and intangible info-structure, probing culture event and lifestyle of the public, collecting scenario data in the field, analyzing people's behavior and activities, combining information architecture and interaction of the urban space, facilitating online involvement and offline participation.

How to develop a research framework for urban experience base on activity theory, what's the new characteristics of human activities in the smart city, how the technologies can support the new urban lifestyle, and what's principles and checklists for conceptual prototype development, these are the foundational issues need to be explored in this research. 


\subsection{Design New Lifestyle in Beijing}

Beijing is the capital of China, often known as the national cultural, political and historical center, currently is undergoing the significant changes in the trends of globalization. These developments crate the diverse, pluralistic, multi-perspective and cross-cultural evidences in Beijing. Along with the acceleration of urbanization, Beijing is facing a lot of challenges, such as social, environmental, housing, transportation, and safety problems. How to rethink the urban problems and give new solutions for better urban lifestyle will be the big challenges to designers for a long period of time.

With the support of urban related computing technologies, the sensor, mobile device, vehicle, building, and public space in the urban areas can be connected in a platform to serving people and their cities. Designer can tracing people's behavior based on social media and personal data through sensor or application, the mobile device and context-aware technology can also provide the proper service when people travel in the city. Under such circumstances, designer will need more efficient tools to handle the holistic perspectives of urban experience from the integration of technology and society.

\subsection{Related Research Projects}

Currently, lots of universities and institutions begin to explore this new field. For example, several research groups and projects of MIT Media Lab are working on how new information technologies and solutions can help citizens to live and interact better with the built environment and nature [1]. Urban informatics research Lab at Queensland University of Technology is revealing the emerging field of urban informatics [2]. Project YOUrban at the Oslo School of Architecture and Design investigates tools and means to creating engagement and a sense of ownership and responsibility towards our physical, social and cultural world [3]. Project Urbanflow in Helsinki aims to envision an operating system for cities, and revolves around situated urban screens and their potential uses [4]. European Commission lunch UrbanIxD project, focusing on human activities, experiences and behaviours around the domain of datarich urban environments. All these researches and projects are starting a new design field in smart city context [5].

\section{Motivation and Position}

The goal of this paper is to build a research framework for designing the social and cultural experience of citizens. The backbone of this process is to understand the behavior of the citizens, their needs and motivations. In smart city, the built environment would be changed to be perceptual, interactive and transformative, which could better support people's urban activities from more and more sophisticated urban life. On one hand, as an interactive space, the city could effectively realize "what you see is what you think" and fully embodies the collective intelligence to our life. On the other hand, smart city system is built based on the social rules, will be the right mediation between the physical environment and human society habits. 


\subsection{Related Theories and Design Tools}

With the help of new information and communication technologies, we can establish the connections between urban and citizens in the real and digital space to promote civic involvement in public service space. For understanding and shaping urban experience in this new context, we need apply various related theories and design tools to reframe the research. Theories will include system theory, complexity theory, ecological science, cybernetics, communication theory, cognitive science, sociology and psychology. Related design methods includes ethnography investigation, sociological research, information architecture, field research, body storming, storytelling, data visualization, urban life documentary, user scenario modeling, user journey, service touch point and blueprint, experience prototype and design patterns. These diverse approaches can be applied to framing a problem space and expose the challenges in urban contexts.

\subsection{Design Interactions in Different Scales}

Interaction design shapes interactive experience between people and product to achieve people's goals and expectations. Interaction designer defines the behavior of product to coordinate relationships between people, people and products, people and the environment, people and service under various situations. The big picture of interactions will concentrate on the relationship between people, context of use and systematic solutions. "Small-scale" interaction is usually applied on intelligent interactive products, furniture and clothing. "Large-scale" interaction involves in the spaces of rooms, buildings, streets and cities. Thus interaction design has extended to a new practice area for shaping the experience between people and environment.

\subsection{Design Perspectives on Smart City}

Smart city is characterized by comprehensive perception, ubiquitous connectivity, pervasive intelligence, and people-centered sustainable innovation which are featured by user innovation, mass innovation, open innovation, and collaborative innovation [6]. Through the structural analysis of the physical facilities and virtual information systems, we can provide the basis for understanding urban life and dealing with city problems. For designing physical space and cities, it should focus on the module, boundary, structure, landscape, usage, intervention and dwellers. For designing information systems and service, it should focus on content, context, identification, activities, behavior, experiences and policies. Design for activity will focus on the people, context of living and intelligent system solutions. City can be seen as the social network, living community and connected organism. Citizen's experience and behavior can only be understood in the context of the socially and culturally interaction with the city, and this point give us an opportunities to involved the activity theory in this research. 


\section{Urban Experience Informed by Activity Theory}

Experience usually refers the feeling and knowledge gained through involvement in or exposure to thing or event. Urban experience is related with human mental activities that emerge, exist and be understood in the interaction of people and the world around them, and the interaction or activities determined by social and cultural factors.

Activity theory was looked as a second-wave, post-cognitivist HCI theory. Designing user interfaces attempted to build an interaction design framework based on combining the checklist of activity theory [7]. Ethnographic approach and Activity Theory also use as participatory design approach to frame the service design process and interpret the complexity of services [8]. Urban experience can be explored from social activities, cultural custom and living environment.

\subsection{Overview of Activity Theory}

Initiated by Vygotsky, Leont'ev, and Luria, activity theory originates in the culturalhistorical psychology. Taking activities as its units of analysis, it examines collective mediated behavior directed towards an outcome [9]. The key elements of activity system include subject, object, tools, rules, community and division of labor. These elements formed four subsystems of production, exchange, consumption and distribution [10]. It also models expertise as an active, collective phenomenon, and provides the understanding of context in which computer-supported activities take place during design and evaluation [7]. Research model informed by Activity theory offers an approach to conceptualize relationships between citizen, city and technologies. (Shown in Fig. 1.)
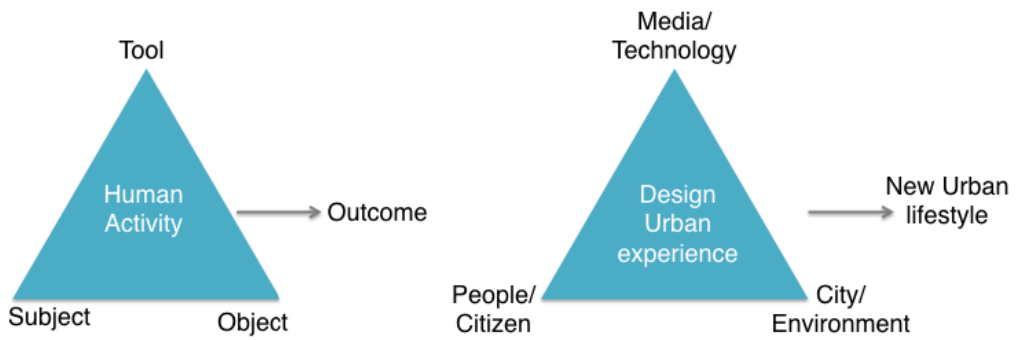

Fig. 1. Research model informed by Activity theory

\subsection{Activity Theory Principles for Urban Experience}

Activity theory is ideal for analyzing user experience because the assumptions of activity theory are much closed with contextual design. Activity theory is embodied in five major theoretical principles as follow: 
- Object-orientedness: There are two kinds of objects, people or things. When we design the urban experience, need find out the social and cultural factors, besides the physical properties of eco-system.

- Mediation \& artifact: Tools shape the interaction between people and physical world. Mobile device and social media become new mediation between citizen and smart city. Tool is also can be people's experience and possession and attachment of life.

- Hierarchical structure of activity: There are three hierarchical levels of interaction, i.e. activities, actions and operations between human and the world. Activity is motive-oriented and composed of actions; user's needs leads to the motive. Action is the goal-oriented and motive defines the goal of actions, Action consists of a series of operation. Operation is depended on the condition, the routine operation will be the unconscious actions, but will become conscious action if condition change. This model gives us a dynamic, context-aware structure to define the interaction.

- Internalization and externalization: Internalization help to build the interaction pattern and operation process in mind before people interact with the external world. Internal mental representations will affect the external interaction, and meanwhile, the external interaction process or pattern can also change people's mental representation. The comprehensive metaphors and language in the intelligent environment will promote the urban interaction. Good urban interaction need follow people's cognition, and it also can help people to nurture good behavior and habits.

- Development: It is very helpful to analysis the time-based interaction, because people's behavior and activity will be changed based on different context.

\subsection{Activity Evaluation Checklist}

The activity checklist is intended to clarify the most important contextual factors of interaction. It can be used at early phases of service system design or for evaluating existing systems. There are two versions of the checklist, the evaluation version and the design version [11]. Below design checklists will be used for this research.

- Means and ends: To identify the main user from citizen, visitor or traveller, and which technology can facilitates and constrains the attainment of users' goals, what are the conflicts between different goals in shaping the sustainable urban lifestyle.

- Environment: To integrate target urban computing, Internet of things and social technology with requirements, tools, resources, and social rules of the environment from the virtual and physical aspects.

- Learning and cognition: To check people's cognitive reflection versus urban interface and service system of activity and support of their mutual transformations with target technology.

- Development: To take the developmental transformation of the urban experience as a whole, and explore the system in a dynamic structure from macro and micro viewpoint. 


\section{$4 \quad$ Case Studies}

Based on the methodology of research through design, this paper will explore the urban interaction models, i.e., people and people, people and service, people and infrastructure in the different contexts. The design process was conducted in the graduate class under the concept of urban media theory and framework [12][13]. Three different places in Beijing include Sanlitun pedestrian bridge, 751 D-park public squares and Wudako subway hub, are chosen for concept development. (shown in Fig. 2.)The main tasks of these studies are to identify, understand and conceptualize the design opportunities in smart city based on the checklist of activity theory.

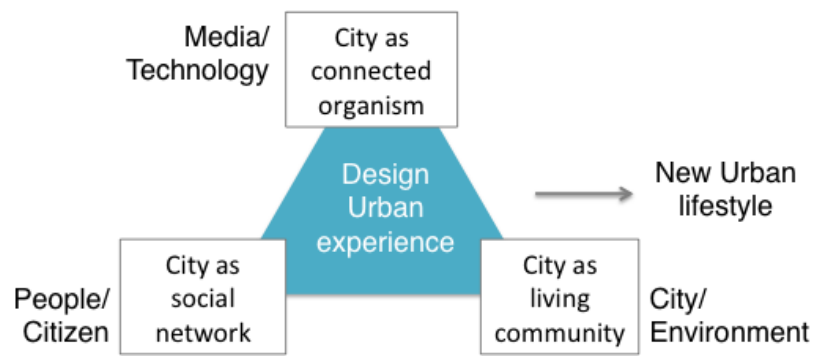

Fig. 2. Practical project fields informed by activity theory

\subsection{City as Connected Ecosystem}

Sanlitun is a young and vibrant international business district. This case focuses on how people interact with urban infrastructure in their everyday life and how they make connection with the city ecosystem. Based on the design checklist of activity theory, four aspects were used to identify the design opportunities.

Means and ends. People's activities on the pedestrian bridge were regarded as subject. Bridge help people to cross the road safely but also need to shape the good interactive experience.

Environment. The pedestrian bridges in Beijing are very typical physical facilitates but usually have the common faces. A smart, social pedestrian bridge can be a connection between people, vehicle and surrounding environment. Bridges are distributed and collaborative, which could also interact and exchange the data of traffic condition, environmental pollution and emergent security.

Learning and cognition. To change "Chinese style of crossing the road", which referring the tendency of large crowds of people to cross roads in disobedience of red lights, the smart pedestrian bridges need to act as an interface to reflect people's needs, activities and values. Through recharge reward points into pedestrian's public transport card to encourage the good habits to take the bridge for crossing road.

Development. The bridge can be regarded as an dynamic operating system, which can transfer human energy to the night lighting, interact with the pedestrian through sensors, those actions could effectively cultivate the healthy and safe urban lifestyle. 
The final conceptual prototype of smart pedestrian bridge shows the context-aware interactions between people, bridge, vehicle and environment. (Shown in Fig. 3.)
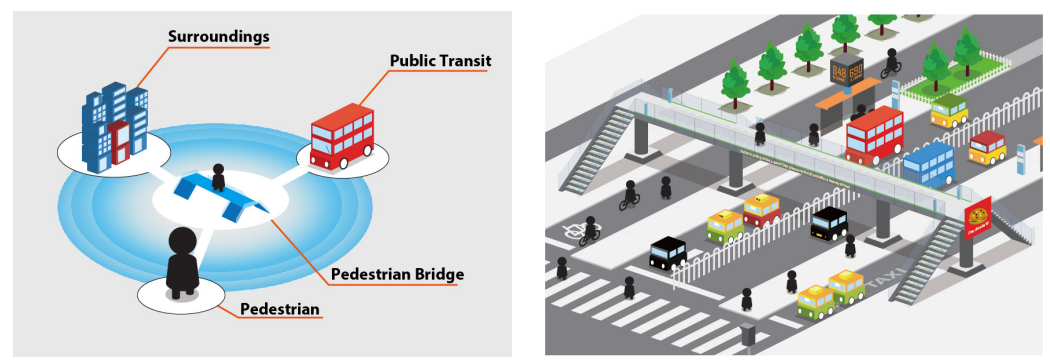

Fig. 3. Smart pedestrian bridge, urban connections and interfaces

\subsection{City as Social Network}

The 751 D-Park was a factory campus near 798 Art District. Now it becomes a stage for cultural and art related events in Beijing. The design checklist of this case as fellow:

- Means and ends. People need to feel their own presence and participation in public venue. People can be attracted by common interest, but it will be a challenge to build ephemeral social network in public event.

- Environment. Citizens can be the sensors to connect with others and environment by ubiquitous computing, Internet of things, etc. A colored wristband was designed to detect the nearby color and change itself color by swinging arms. Then the wristband can create different dynamic groups during the event.

- Learning and cognition. Lots of people came to the music festivals or concerts for social reasons. The social behavior of conformist mentality will shape the coexperience, emotional interaction on site.

- Development. Sharing and exchanging color will be not only for creating atmosphere but also can collect the individual data and present it on big screen in the stage during the whole event. The wristband link people in the ephemeral social network and will create dynamic media system in the public space.

- The final deliverable is conceptual wristband prototype called Co-pulse, which could link and form the emotional-based social network in a public event. (Shown in Fig. 4.)
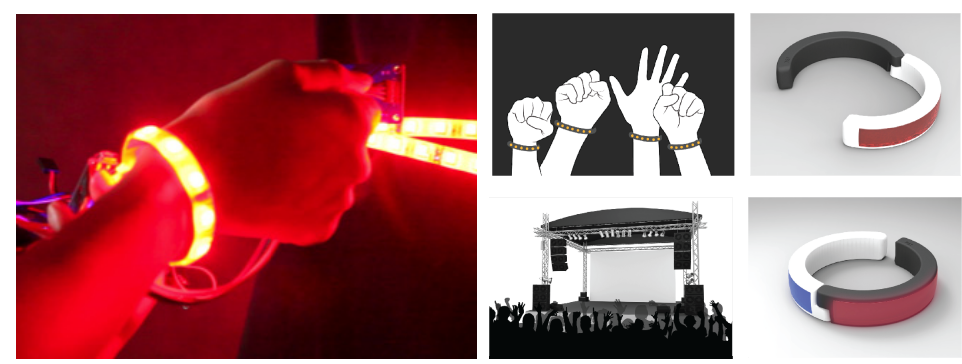

Fig. 4. Co-pulse, social interactive wristband for public event 


\subsection{City as a Living Community}

Wudaokou is a transportation hub in the Haidian District of Beijing. In this project, public transportation service was applied to help citizens to manage every day life. The design checklist of this case as fellow:

- Means and ends. This project focuses on urban mobility issues in public life, which is based on the principle of energy flow and energy conservation to become a public service system by linking different service touch points. The prototype is mobile application that provides commuter with personal transportation and encourages people to take healthy ways to workplace. It includes three main parts: route-arrangement, eco-travelling and information sharing.

- Environment. Based on location based service and cloud computing, traffic, weather and personal data can be well integrated to help people arrange their routes efficiently, and encourage people to use healthier ways travel such as bicycles, public transport, walking etc.

- Learning and cognition. The project will analyze the relations between individual behaviors of citizens and groups habits to explore the interaction pattern of balancing comfortable and sustainable transportation.

- Development. The liquidity of information will guide the participatory behaviors of public and shape the holistic urban mobility experience in a long period. The mobile application and smart urban transportation network will record the personal data to keep the traveller go smoothly in his journey.

The final deliverable is conceptual personal urban mobility application called Balance Flow, which could help people to arrange their daily transportation and shape sustainable living habits. (Shown in Fig. 5.)
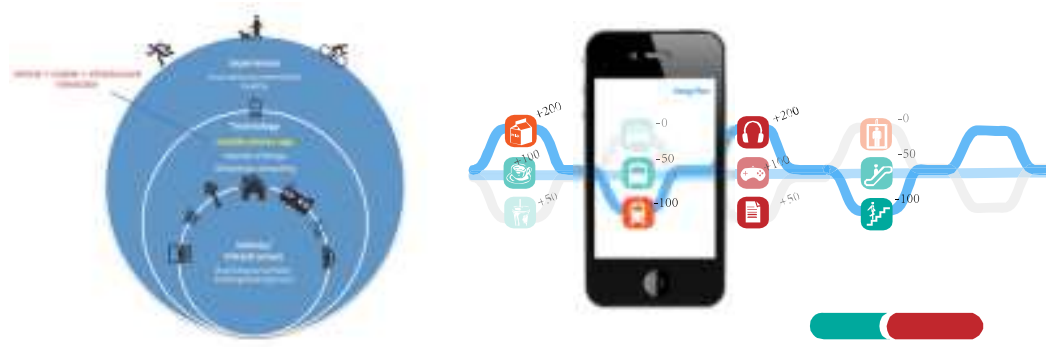

Fig. 5. Balance Flow, personal urban mobility application

\section{$5 \quad$ Discussion and Future Works}

Smart city change the built environment to a sensible, interactive and transferred place, which can support human activities in all levels. New concepts will be needed to effectively support the implementation of the eco-city environment, and intelligently response to the changes of urban lifestyle. Accelerating expansion of urban functions and openness of the urban life make our city became a complex system. 
We have to apply design thinking to find out the new solutions, which could better deal with the core problem of smart city.

The smart city is a complex system of the combination of human experience and the built environment. Future research on urban interaction and service design of smart city will mainly focus on the exploration in tangible city and intangible information to find more possibilities of user experience and service innovation after the combination of reality and virtual cyberspace. Activity-based design will enrich the human centered methods, lead to situational, participatory, and pervasive intelligent service in city. A holistic framework and urban interaction design patterns will be developed in the next step research.

\section{Conclusions}

This paper explored the new perspective of combining the social and cultural activities into physical built environment. It provided the new methods and examples for developing the smart city eco-system and shaping the urban experience. Based on the methodology of research through design, three different contexts in Beijing, including Sanlitun pedestrian bridge, 751 D-park public squares and Wudako subway hub are chosen for concept development. This research method focused on finding the opportunities from citizens' behavior and urban lifestyle, final conceptual deliverables represented the main ideas of city as connected organism, social network and living community. It can also help the planer and manager in Beijing to better understand the planning and renovation of the existing urban system, improve the quality of real city life, and develop new integrated application and service to enhance the urban interaction experience between the people and intelligent city system.

Acknowledgements. The design researches and prototypes in this paper involve the results of postgraduate courses and project of urban media. Many thanks for Mr. Christopher Kirwan to co-conduct the course with me, and for the related students including Xingjian Cui, Junjie Yu, Shen Li, Wang Luobin, Lin Han, Simo Feng, Menglin Ye, Jingli Zhu, and Wei Gong, I express my sincere thanks to their works.

\section{References}

1. MIT Media Lab, http: / /www. media.mit. edu/research/groups-projects

2. Urban Informatics Research Lab, http: / / www . urbaninformatics . net

3. YOUrban, http://yourban. no

4. Urbanflow, http://helsinki.urbanflow.io/

5. UrbanIxD, http: / / urbanixd.eu

6. Song, G., Wu, L.: Smart City in Perspective of Innovation 2.0. 0, Journal of Beijing University of Posts and Telecommunications (Social Sciences Edition) 14(4), 8-15 (2012)

7. Uden, L., Willis, N.: Designing User Interfaces using Activity Theory. In: Proceedings of the 34th Hawaii International Conference on System Sciences (2001)

8. Sangiorgi, D., Clark, B.: Toward a Participatory Design Approach to Service Design. In: Participatory Design Conference, 2004-07-272004-07-31, Toronto (2004) 
9. Vygotsky, L.S.: Mind and Society. Harvard University Press, Cambridge (1978)

10. Jonassen, Peck, Wilson: Learning with technology: A constructivist perspective (1999)

11. Kaptelinin, V., Nardi, B., Macaulay, C.: The Activity Checklist: A tool for representing the "space" of context. Interactions Magazine, 27-39 (July 1999)

12. Fu, Z., Zhang, X.: Designing for Social Urban Media: Creating an Integrated Framework of Social Innovation and Service Design in China. In: HCI International 2011(the 14th International Conference on Human-Computer Interaction), Orlando, U.S.A., July 14-19 (2011)

13. Kirwan, C.G.: Urban media: a design process for the development of sustainable applications for ubiquitous computing for livable cities. In: Proceedings of the 2011 ACM Symposium on The Role of Design in UbiComp Research \& Practice, Beijing, China (September 2011) 